\title{
Evaluation of Metal-Active Gas Double-Sided Double-Power Arc Welded Joints of High-Strength Low-Alloy Steel
}

\author{
Y. X. Chen, ${ }^{a, b, 1}$ C. D. Yang, ${ }^{\text {b X. J. Wang, }{ }^{c} \text { and S. B. Chen }}{ }^{\mathrm{b}}$ \\ a School of Mechanical and Electrical Engineering, Hohai University, Changzhou, China \\ ${ }^{\mathrm{b}}$ Intelligentized Robotic Welding Technology Laboratory, School of Materials Science and Engineering, \\ Shanghai Jiao Tong University, Shanghai, China \\ c Jiangsu University of Science and Technology, Zhenjiang, China \\ ${ }^{1}$ cyx1978@yeah.net
}

High-strength low-alloy steel $50 \mathrm{~mm}$ thick is well joined by metal-active gas double-sided doublepower arc welding, which does not require preheating, postheating, and back chipping. Mechanical properties of the weld seam and base metal were investigated. Results of the tensile test indicate that the strength of the weld seam is about $862.73 \mathrm{MPa}$ and its average elongation is 20.74\%. The hardness of the base metal and weld zone is 299 and $361 \mathrm{HV}$, respectively. The maximum hardness (395 HV) is observed in the heat-affected zone. The average toughness of the face and root sides of the weld center is 75 and $71 \mathrm{~J}$, respectively.

Keywords: high-strength low-alloy steel, double-sided double arc welding, multilayer welding, mechanical properties.

Introduction. High-strength low-alloy (HSLA) steel is a type of structural steel, which is often used in ship hulls, pressure vessels, oil and gas pipelines, due to its excellent mechanical properties, outstanding resistance to corrosion and good weldability. Up to now, HSLA steel welding has been successfully provided by such welding techniques as arc welding (AW), in particular, gas metal arc welding (GMAW), electron beam welding (EBW), laser welding (LW), etc.

Currently, the AW procedure involves the following steps: preheating, GMAW at one side, then back chipping by carbon arc air gouging, polishing, magnetic particle examination, the repeated preheating, GMAW at the other side, final postheating, etc. This complex procedure is characterized by a low productivity, requires a large-scale filler metal addition, and produces large distortions due to the nonuniform welding shrinkage [1]. Fortunately, EBW and LW processes, which involve deeper subsurface layers of the welded material, can overcome the above disadvantage. However, both processes require a close tolerance joint fit-up and imply high operation costs. Therefore, there is an urgent requirement for developing advanced welding techniques with deep welding penetration to join HSLA steel structures and components, especially those with a high thickness.

Recently, a new high-efficiency technique, which requires no back chipping, namely, the double independent power double-sided double arc welding (DSDAW), becomes more and more popular in the HSLA welding applications. In the welding process, the backing pass/run is produced by the double-sided pulse gas tungsten arc welding (GTAW), while other passes are made with the double-sided GMAW. The operation process is quite simple, and the productivity is very high. However, the majority of studies on this welding technique are focused on either thin or medium-thickness plate welding structures [2-4]. Thus, the thick-plate welding needs to be developed and verified, in order to widen the applications of the newly emerged techniques. Meanwhile, more efforts are still required to evaluate the effect of welding parameters on microstructure and mechanical properties of thick-plate weld structures. 
In the present work, the microstructure and mechanical properties of a thick plate of Q690 steel welded by the metal active gas (MAG) welding DSDAW process without preheating, postheating and back chipping are investigated.

\section{Experimental Procedures.}

1.1. Material and Welding Procedure. The new DSDAW technology is a double, independent power type DSDAW, which is different from a single-power one presented by Zhang [4]. The basic principle of this new welding technique is illustrated by Fig. 1. The backing pass is produced by the double-sided double pulse GMAW; two weld torches are placed at the front and back sides of the plate and are individually supplied by weld power 1 and power 2 .

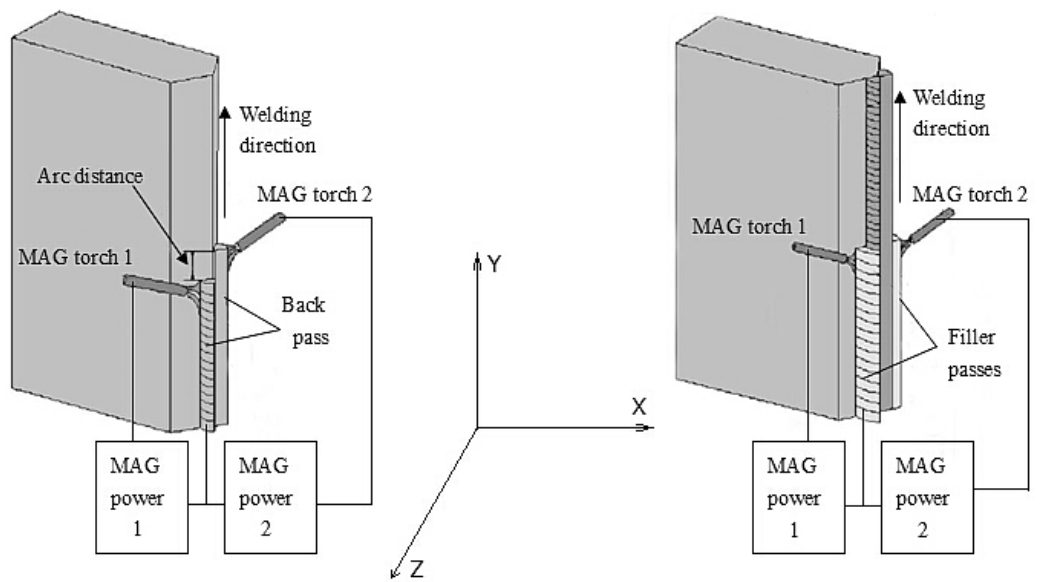

Fig. 1. Scheme of the double-sided double MAG technique.

Double-sided double MAG torches (see Fig. 1) ensure the required arc distance to realize an asymmetric DSDAW in the back pass, while other passes are produced by the double-sided double GMAW. Two MAG torches are symmetrically placed on both sides of the plate and supplied by two independent weld powers individually. Here $Y$ is the welding direction, $Z$ is the thickness direction, and $X$ is the width direction, which is normal to the welding direction.

In this study, welding experiments were carried out to investigate the new DSDAW method, which requires no preheating, postheating, and back chipping and involves two independent multipass welding arcs. The total weld process consists of 24 passes, e.i., 12 passes are made on the front and back sides of the plate. The base material is Q690 steel with dimensions of $50 \times 70 \times 240 \mathrm{~mm}$, a double-V symmetric groove with an opening angle of $45^{\circ}$, and the root gap of $4 \mathrm{~mm}$. The filler material is YM-80A alloy welding wire with a diameter of $1.2 \mathrm{~mm}$. The chemical composition of the base metal and electrode wire is listed in Table 1. The shielding gas flow rate is 201 per minute and welding speed is $240 \mathrm{~mm}$ per minute. The welding process is performed using gas metal arc according to the standard welding parameters.

$\mathrm{T}$ a b 1 e 1

Chemical Composition of Base Metal and Filler Wire

\begin{tabular}{||c|c|c|c|c|c|c|c|c||}
\hline \multirow{2}{*}{ Material } & \multicolumn{9}{|c||}{ Element } \\
\cline { 2 - 9 } & $\mathrm{C}$ & $\mathrm{Si}$ & $\mathrm{Mn}$ & $\mathrm{P}$ & $\mathrm{S}$ & $\mathrm{Ni}$ & $\mathrm{Cr}$ & $\mathrm{Mo}$ \\
\hline Q690 steel & 0.10 & 0.23 & 0.54 & 0.009 & 0.007 & 4.10 & 0.53 & 0.36 \\
Filler metal & 0.07 & 0.34 & 0.74 & - & - & 1.23 & - & - \\
\hline
\end{tabular}


The welded joints were cut out perpendicular to the welding direction and coldmounted, in order to examine the microstructure of the fusion zone, heat-affected zone (HAZ), and base metal. The mounted specimens were manually ground, polished, and etched using 5 vol. $\% \mathrm{HNO}_{3}-95$ vol. $\% \mathrm{C}_{2} \mathrm{H}_{5} \mathrm{OH}$ solution. The microstructure and fracture morphology of specimens were analyzed by scanning electron microscope (SEM), while their chemical composition was characterized by the energy disperse spectroscopy (EDS). A universal testing machine was used for the experimental determination of the ultimate tensile strength and elongation of the specimens.

\section{Results and Discussion.}

2.1. Hardness Variation. The Vickers hardness measurements of the weld metal were performed in the HAZ, fusion line, and weld center, respectively. The respective specimens were cut out from the face side ( $2 \mathrm{~mm}$ below the weld metal surface) and the root side (25 mm below the weld metal surface) of the weld metal, as shown in Fig. 2a. At least three specimens with a spacing of $0.5 \mathrm{~mm}$ were tested in each hardness test, and the average values were plotted in Fig. 2b. Hardness values for the base metal and weld zone are 299 and $361 \mathrm{HV}$, respectively. The maximum hardness value (395 HV) is observed on the HAZ face side. These results can be exlpained via the analysis of the weld metal microstructure.

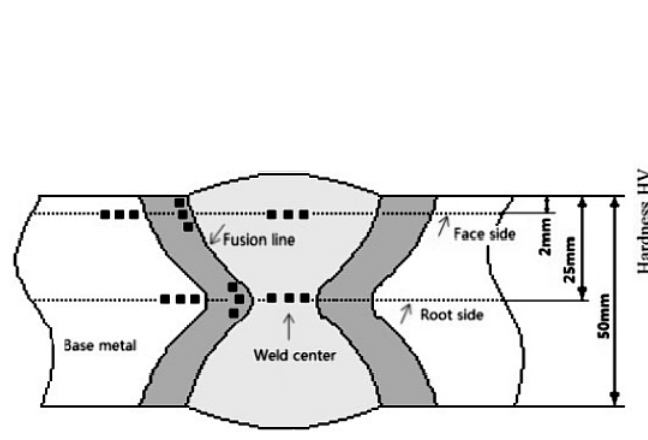

a

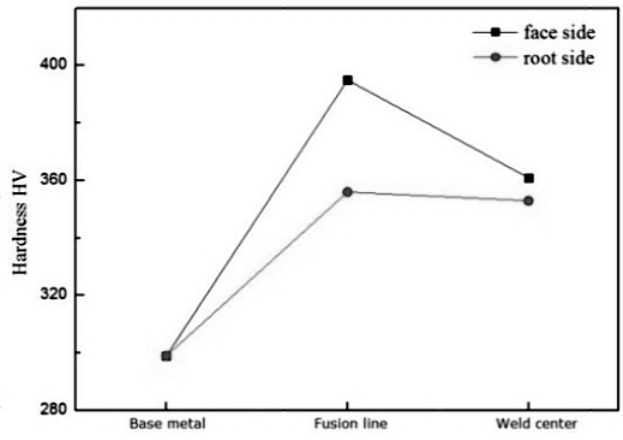

b

Fig. 2. Hardness measurement positions (a) and hardness profile (b) of the weld metal.

The microstructure of low-alloy steels is quite complex, consisting of different morphologies of ferrite (including allotriomorph ferrite, ferrite side plates, and acicular ferrite), bainite, microphases and some inclusions. Microphase is a collective term for small fractions of martensite, degenerated pearlite, and retained austenite that develops from saturated austenite at the last stage of transformation.

Figure 3 shows a typical cross-sectional macrograph of the multipass welded joint, which is composed of weld metal with coarse grain zone, overheated zone, and base metal. During DSDAW, the arc heating and chilling thermal cycles are responsible for the formation of acicular ferrite, granular bainite and martensitein weld metal as shown in Fig. 3c. The hardness of martensite phase is higher than ferrite phase. Therefore, the weld center has a higher hardness than HAZ.

Moreover, in all welded specimens, the maximum hardness occurs at the surface of fusion line. This is attributed to higher cooling rates due to the chilling effect of the adjacent base metal. During welding, high peak temperature thermal cycles are responsible for austenite grain growth in the base plate near the weldment. The grain size decreases as the peak temperature falls monotonically with distance from the fusion line. Therefore, the coarse grain zone is located next to the fusion line, while the fine grain zone is located marginally away from the fusion line. Meanwhile, the martensite phase growth decreases 


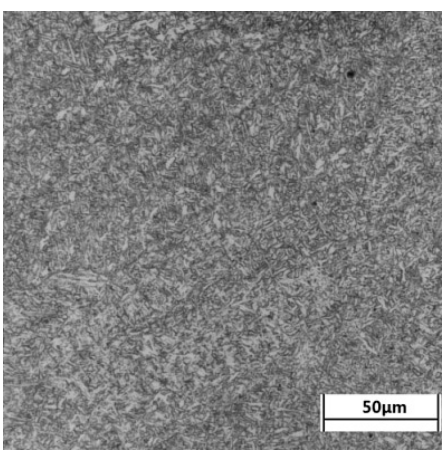

$\mathrm{a}$

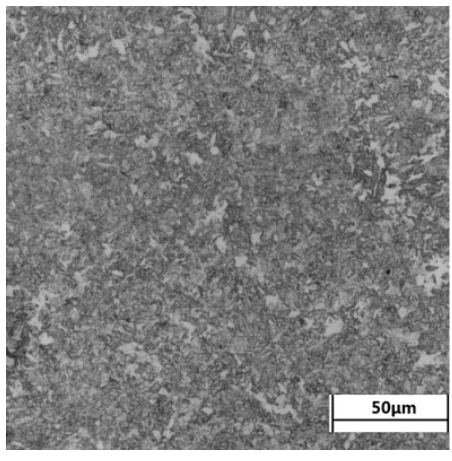

c

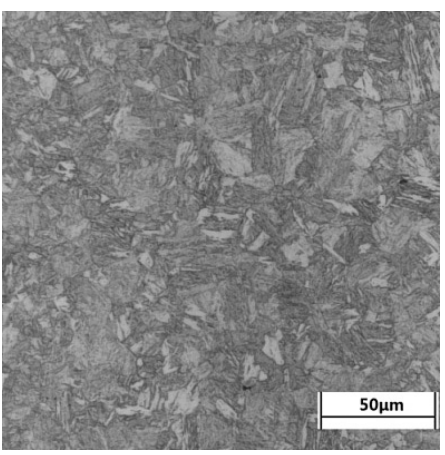

b

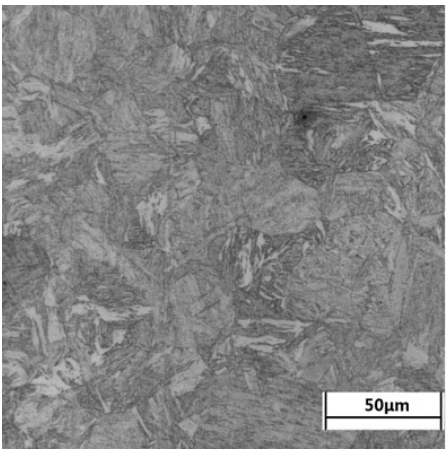

d

Fig. 3. Microstructure of DSDAW weld metal: (a) base metal; (b) overheated zone; (c) weld metal; (d) coarse grain zone.

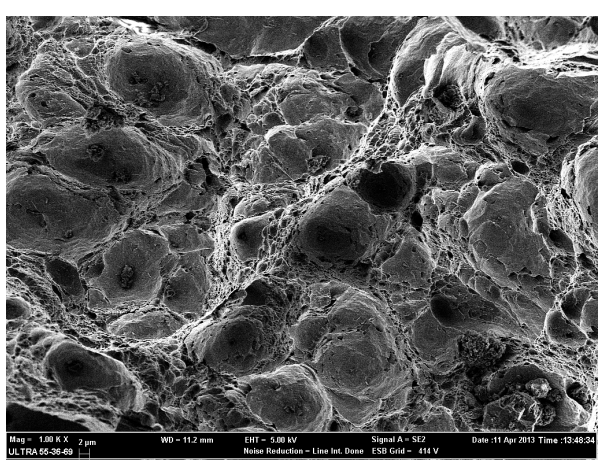

a

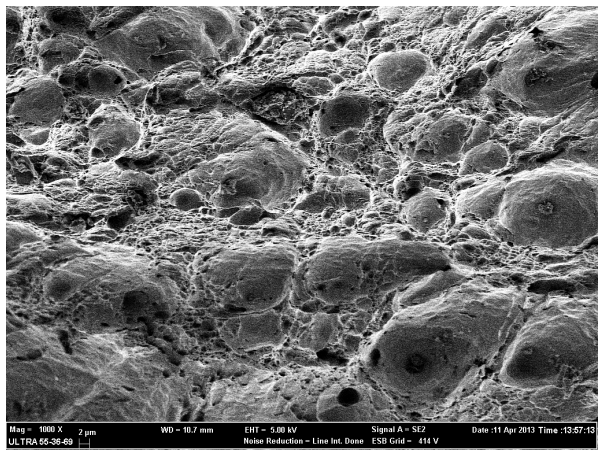

$\mathrm{b}$

Fig. 4 Fracture morphologies of weld (a) and fusion line (b).

with distance from the fusion line. As a result, various sections of the HAZ develop different microstructures with different mechanical properties.

2.2. Tensile Strength. It is found that the average tensile strength of welded joint is $862.73 \mathrm{MPa}$, the average elongation $20.74 \%$. Figure 4 show the fracture micromorphologies of weld and fusion line by SEM, which explains the scatter between the tensile test results. Compared with fusion line in surface fracture, the dimples of weld are deeper and distributed more uniformly, indicating a higher toughness. Moreover, more second-phase particles are dispersed in the dimples at the fracture surface of the fusion line, which phenomenon implies a higher hardness. However, the improved mechanical properties of 
weld are attributed to the finer grain size. In the process of DSDAW, the second heat cycle is induced by the rear pass, which can be treated as a post-heating action to the fore pass. Similarly, the fore pass provides a preheating for the rear pass and, consequently, the resulting grain size can be reduced.

2.3. Charpy Impact Toughness. The impact test results for each specimen and thier average values, which are listed in Table 2, indicate that the Charpy impact toughness values correlate well with hardness and tensile properties. A general increase in the Charpy impact toughness with the distance from the weld fusion line is observed. The toughness of the weld face is higher than that of the weld root. There are several parameters affecting the impact toughness of the weld joints:

(i) hardness (or strength) level;

(ii) microstructure (share of different regions in the Charpy notch zone);

(iii) characteristics of inclusions like volume fraction, size, and spacing [5].

$\mathrm{T}$ a b 1 e 2

All-Weld Metal Charpy Absorbed Energy

\begin{tabular}{||l|c|c||}
\hline \multicolumn{1}{|c|}{ Notch location } & Discrete values $(\mathrm{J})$ & Average value $(\mathrm{J})$ \\
\hline Weld center (face/root) & $76,78,72 / 66,74,72$ & $75 / 71$ \\
\hline Fusion line (face/root) & $76,76,60 / 62,68,60$ & $71 / 63$ \\
\hline Fusion line + $2 \mathrm{~mm}$ (face/root) & $162,178,152 / 162,152,150$ & $164 / 155$ \\
\hline Fusion line +5 mm (face/root) & $160,162,166 / 92,160,156$ & $163 / 136$ \\
\hline
\end{tabular}

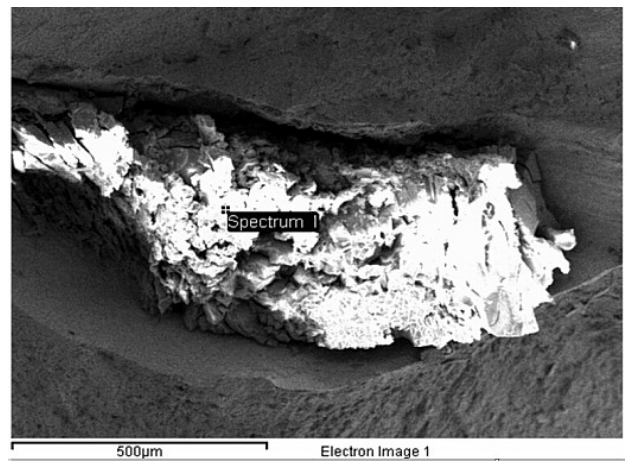

a

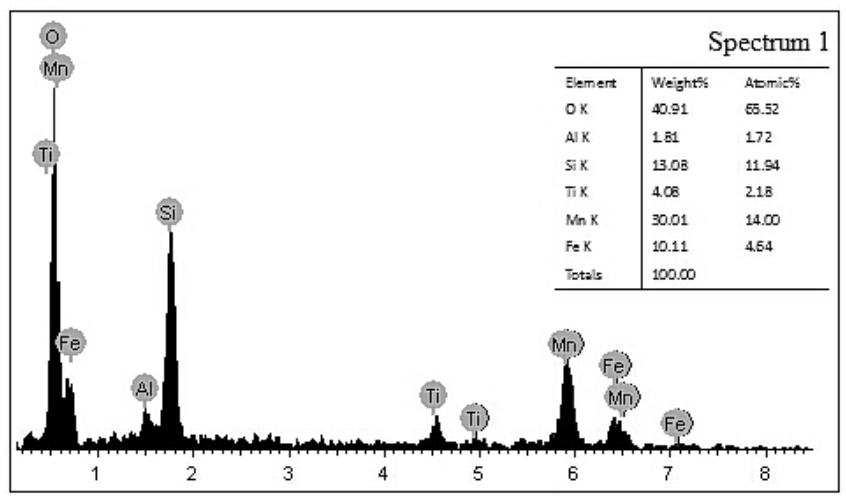

$\mathrm{b}$

Fig. 5. Microstructure (a) and EDS results (b) for the root side in the weld center. 
In generally, the toughness value decreases with hardness (or strength), because the material susceptibility to plastic deformation reduces, and hence work of fracture decreases. Some microstructural constituents, like an acicular ferrite, have higher strength and hardness than other ferrite morphologies, but also are characterized by a high level of the impact toughness [5-7]. Microstructures like bainite, which includes parallel bands with low-angle boundaries, also have a low impact toughness.

However, one of the measured Charpy impact toughness values, which corresponds to th weld foot in the weld center, is $66 \mathrm{~J}$, which is less than other values ( 74 and $72 \mathrm{~J}$, respectively), as is shown in Table 2. To clarify this problem, a comprehensive analysis of the fusion and solidification processes of the Q690 workpiece during multipass welding is required. Figure $5 \mathrm{a}$ illustrates the microstructure of the root side in the welding center, while the EDS analysis results presented in Fig. 5b indicate that the inclusion particle is mainly composed of $\mathrm{O}, \mathrm{Mn}, \mathrm{Si}$, and Fe elements. In multipass welds, the shielding gas or the addition of $\mathrm{CO}_{2}$ or $\mathrm{O}_{2}$ to argon interacts with the weld pool and causes oxidation, which results in some loss of alloy constituents and produces inclusions in the weld. Especially, inclusions like welding slag $\mathrm{SiO}_{2}$ should be considered in the multipass welds. Presence of a very high volume fraction of inclusions may initiate a premature ductile fracture [8]. In general, the presence of inclusions is detrimental to weld properties.

\section{Conclusions}

1. Q690 HSLA steel of $50 \mathrm{~mm}$ in thickness is effectively joined by DSDAW process without preheating, postheating and back chipping.

2. The average tensile strength of DSDAW is $862.73 \mathrm{MPa}$, and the average elongation is $20.74 \%$. Compared with fusion line, the dimples on the fracture surface of weld are deeper and more uniformly distributed, which indicates a higher toughness.

3. Hardness in the base metal and weld zone is 299 and $361 \mathrm{HV}$, respectively. The maximum value of hardness ( $395 \mathrm{HV}$ ) occurs in the HAZ. Furthermore, the higher strength of weld metal is as a result of faster cooling rate which leads to formation of a higher share of martensite.

4. The average toughness values of the face and root sides of the fusion line are 71 and $63 \mathrm{~J}$, respectively. The average toughness values of the face and root sides of the weld center are 75 and $71 \mathrm{~J}$, respectively. The impact properties of weld metals improve with the share of acicular ferrite in as-deposited regions. Nevertheless, the toughness reduction may be due to inclusions like the remaining slag in the multipass weld.

Acknowledgments. The authors would like to express their gratitude to Shanghai Jiao Tong University for the financial support of this study through Grant No. 201310211468. Also, this work was supported by Changzhou Natural Science Foundation Project No. CJ20130031.

1. H. J. Zhang, G. J. Zhang, C. B. Cai, et al., "Numerical simulation of three-dimension stress field in double-sided double arc multi-pass welding process," Mater. Sci. Eng. A, 499, 309-314 (2009).

2. Y. B. Zhao, Z. L. Lei, Y. B. Chen, and W. Tao, "A comparative study of laser-arc double-sided welding and double-sided arc welding of $6 \mathrm{~mm} 5$ A06 aluminium alloy," Mater. Design, 32, 2165-2171 (2011).

3. M. Mirzaei, R. Arabi Jeshvaghani, A. Yazdipour, and K. Zangeneh-Madar, "Study of welding velocity and pulse frequency on microstructure and mechanical properties of pulsed gas metal arc welded high strength low alloy steel," Mater. Design, 51, 709-713 (2013). 
4. Y. M. Zhang, C. Pan, and A. T. Male, "Welding of austenitic stainless steel using double sided arc welding process," Mater. Sci. Technol., 17, 1280-1284 (2001).

5. M. H. Avazkonandeh-Gharavol, M. Haddad-Sabzevar, and A. Haerian, "Effect of copper content on the microstructure and mechanical properties of multipass MMA, low alloy steel weld metal deposits," Mater. Design, 30, 1902-1912 (2009).

6. M. Gao, Y. Cao, X. Y. Zeng, and T. X. Lin, "Mechanical properties and microstructures of hybrid laser MIG welded dissimilar Mg-Al-Zn alloys," Sci. Technol. Weld. Join., 15, No. 7, 638-645 (2010).

7. Y. B. Zhao, Z. L. Lei, Y. B. Chen, and W. Tao, "A comparative study of laser-arc double-sided welding and double-sided arc welding of $6 \mathrm{~mm} 5$ A06 aluminium alloy," Mater. Design, 32, 2165-2171 (2011).

8. S. Mukhopadhyay and T. K. Pal, "Effect of shielding gas mixture on gas metal arc welding of HSLA steel using solid and flux-cored wires," Int. J. Adv. Manuf. Technol., 29, 262-268 (2006). 